\title{
THE OPTIMUM DESIGN OF INTERVAL TYPE-2 FUZZY CONTROLLER FOR 5 DOF ROBOTIC MANIPULATOR
}

\author{
Ahmed A. Al-Jazaeri', Mohammed Z. Al-Faiz ${ }^{2}$ \\ ${ }^{1}$ Department of Control and Systems Engineering, University of Technology, Iraq \\ ${ }^{2}$ Department of Systems Engineering, Al-Nahrain University, Iraq \\ ahmedalaa1975@yahoo.com ${ }^{1}$,mzalfaiz12@coie.nahrainuniv.edu.iq ${ }^{2}$ \\ (Received: 17/01/2018; Accepted: 07/03/2018)
}

\begin{abstract}
The robotic manipulator using intelligent controller has become a research hotspot for most robot manufacturers all over the world. Robotic manipulator systems have disadvantages, such as high nonlinearity, slow response, and uncertainty; Type-2 FLC can be a solution to these drawbacks. A fuzzy controller for 5250 Robotic Manipulator (RM) Lab-Volt (LV) is designed to track the joints position with new axis. The RM joint is processed as a single case. The Particle Swarm Optimization and Genetic Algorithm are used. The new design was implemented of type-2 fuzzy logic based PSO as four controllers (T1FLC, T2FLC, PSOT1FLC, and PSOT2FLC). The most important parameters of Type-2 Fuzzy are gains (input /output) and foot of print uncertainty (FOU). Four cases are implemented for each joint (fixed FOU fixed Gain, fixed FOU variable Gain, variable FOU fixed Gain and variable FOU variable Gain). The experimental results for PSOT2FLC gave a good transient response with minimum integral absolute error IAE and minimum overshoot.
\end{abstract}

Keywords- Type-2 Fuzzy Logic Controller; Type-1 Fuzzy Logic Controller; Particle Swarm Optimization; Genetic Algorithms; Robotic Manipulator; MATLAB Package.

\section{INTRODUCTION}

RM the common and familiar type of robot. Robotic systems have these days represent a very important sector of many industrial processes such as in manufacturing, military, and civilian [1,2]. The serial body structures are the first design of robotic manipulators. In this kind of robots, joints are attached to each other in links. This leads to easy methods of kinematics and dynamics but also lower precision and increase in manipulator's weight with lower repeatability. The complex and coupled nonlinear systems problems in robotic manipulator signal tracking are no solved; therefore, the cause for this paper are: to build and implement optimal control action for RM, to track the desired signal with minimum error, to overcome high uncertainty.

Work contributions are summarized as:

- New developing of the type-2 fuzzy logic controller design based PSO and genetic algorithm (GA) techniques, and compared responses between PSOT2FLC and GAT2FLC.

- The novelty is concerned to choose the membership-function to a very good transient response, minimum error based PSO and overall analysis T2FLC according to FOU and Gains.

- The unsymmetrical memberships function represented as triangles with the same top head.

- Minimizing the tracking error of the robotic manipulator, again by optimal choose for input and output gains.

- Verifying experimentally the capability of the proposed on-line type-2 fuzzy logic controller based PSO in tracking path by using Lab-Volt 5250 robotic manipulator.

https://ijict.edu.iq 


\section{A. The Detail for Lab-Volt 5250 RM Framework}

Those Lab-Volt 5250 robotic controllers need five degrees of option (5 DOF) Furthermore an end-effector to item grasping. There need aid (3) main joints (joints of arm) Elbow, Shoulder, and Base, those secondly joints (joints of the wrist) would roll, and pitch. Fig. 1 indicates the photo of the lab-volt 5250 robotic manipulators. Those ranges from claiming lower arm joints would (zero- one hundred fifty-five) in degrees, upper arm (zero - two hundred forty) in degrees and driven Toward An dc servo motor, and the ranges of the wrist revolution joints would (zero - one cycle) in degrees Furthermore wrist pitch (zero - one hundred fifty five) in degrees, Likewise indicated over same Fig. 1. DC servo motor of the joint base is "General Motor 9421". The Gear Box is 1277/1-1. The joint of Shoulder sort will be "General Motor 9431" which diminishment through pulleys. The Joint of the elbow is "General Motor 9431" through Gear Box 1277/10-1. The properties of wrist motors need aid those same for roll and pitch, eas takes after: the max. Torque will be three kg. Cm, maxi. Present will be $1.25 \mathrm{~A}$, the begin current will be $0.156 \mathrm{~A}$. The LabVolt 5250 is a five joints PC controlled arm. Each joint would freely be controlled Toward a closed-loop servo motor system $[5,6]$.

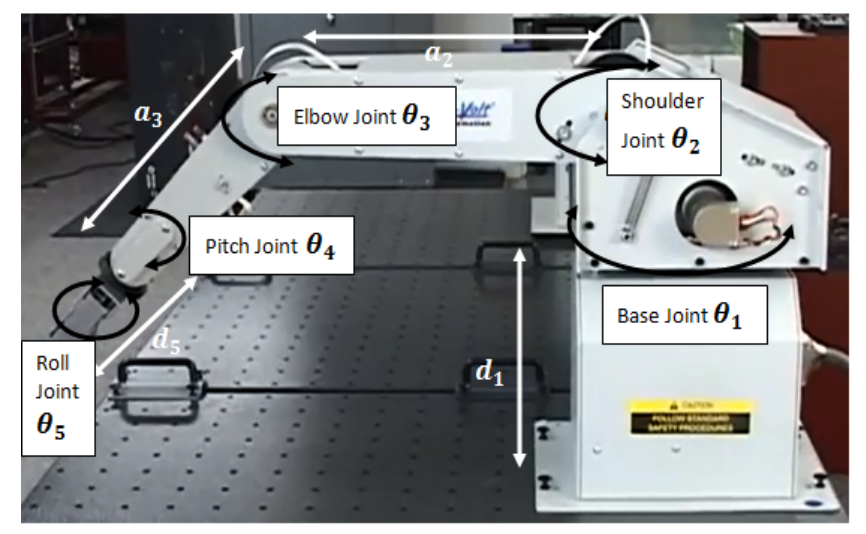

Figure 1. Photo of the lv 5250 RM for joints ranges.

\section{B. The Lab-Volt 5250 RM Forward Kinematics}

Robot joints were assessed, in this way the joint variable may be $\Theta i$ for those robot joint. Those entire kinematic parameters of the Lab-Volt 5250 Robotic controller were measured, more recordings done in Table I.

TABLE I

MEASURED DENAVIT-HARTENBERG PARAMETERS

\begin{tabular}{|c|c|c|c|c|}
\hline $\begin{array}{c}\text { (i) } \\
\text { Joint } \\
\text { Link }\end{array}$ & $\begin{array}{c}\text { (Oi ) } \\
\text { Variable } \\
\text { in } \\
\text { (degree) }\end{array}$ & $\begin{array}{c}\text { (di) } \\
\text { Offset } \\
\text { in } \\
\text { (mm) }\end{array}$ & $\begin{array}{c}\text { (ai ) } \\
\text { Twist } \\
\text { angle in } \\
\text { (degree) }\end{array}$ & $\begin{array}{c}\text { (ai) } \\
\text { Length in } \\
\text { (mm) }\end{array}$ \\
\hline 1 & O1 & 385 & 90 & 0 \\
\hline 2 & O2 & 0 & 0 & 360 \\
\hline 3 & O3 & 0 & 0 & 230 \\
\hline 4 & O4 & 0 & 90 & 0 \\
\hline 5 & O5 & 165 & 0 & 0 \\
\hline
\end{tabular}


Kinematics parameters exhibited might have been resolved to utilize this setup concerning illustration starting pose. Zero position structure of LV5250RM is shown in Fig. 2. Axis of the base is defined as; the rotational axis is Z_0, which is the X_0 axis is aligned with the physical axis of the cylindrical base, and vertical to the work table. That point finishes the 3 rd axis system (X_0, Y_0, Z_0). Eventually perusing utilizing the right-hand rule. Base root has been put in the beginning $[7,8]$.

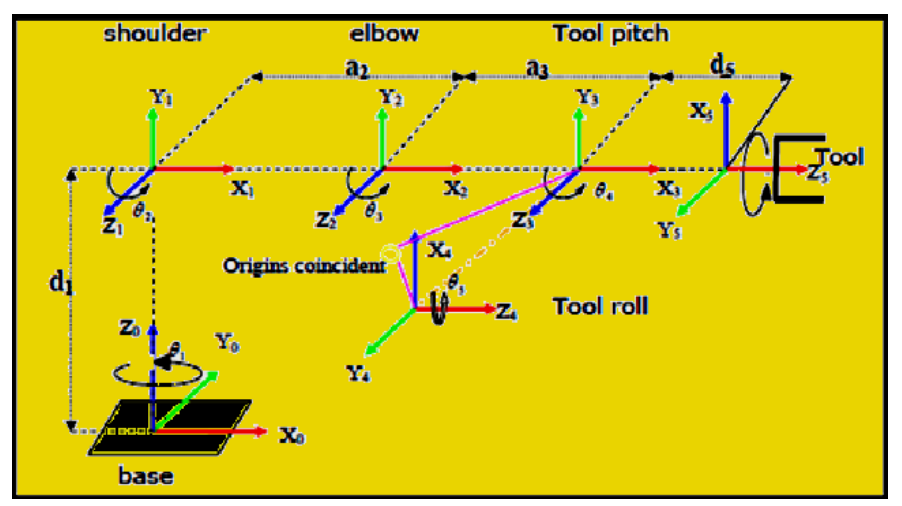

Figure 2. Home Position of Robot Arm (zero position).

Kinematics parameters exhibited might have been resolved to utilize this setup concerning illustration starting pose. Zero position structure of LV5250RM is shown in Fig. 2. Axis of the base is defined as; the rotational axis is Z_0, which is the X_0 axis is aligned with the physical axis of the cylindrical base, and vertical to the work table. That point finishes the 3rd axis system (X_0, Y_0, Z_0). Eventually perusing utilizing the right-hand rule. Base root has been put in the beginning $[7,8]$.

Axis of pivoting $\left(Z_{-} 1\right)$ of the shoulder joint is level with respect to the fill-in floor plane, i.e. perpendicular to the X_0, Y_0-plane. Those crossing point for $Z_{-} 0$ What's more $Z_{-} 1$ will be speaking to those beginning of the span (X_1, $\left.Y_{-} 1, Z_{-} 1\right)$, that hub is resolved Eventually perusing those cross product $\left(Z_{-} 0 \times Z_{-}\right.$1) the RHR is connected. That point figures out the heading of the third axis $Y_{-} 1$ toward utilizing RHR for $X_{-} 1$ and $Z_{-} 1$. Those certain bearing of the $Z_{-} 0$ what is more $Z_{-} 1$ axes need aid picked on understanding for RHR dives of the certain course of the precise position Ө_1 Also $\Theta \_2$, individually. The revolution axis $Z \_2$ will be parallel to the past joint pivoting axis $Z \_1$, in this manner $\mathrm{X} \_1$ hub will be along the as a relatable point ordinary from claiming them. Those third axis $Y_{-} 2$ with finish those span may be characterized as stated by RHR, the crossing point about these hub speaks to those root for this outline (X_2, Y_2, Z_2). Those revolution axis $Z \_3$ may be parallel to the past joint pivoting axis $Z \_2$, Consequently $X \_3$ axis is along those normal typical of them. Those third axis $\mathrm{Y}_{-} 3$ on complete those span may be characterized as stated by RHR, those crossing point of these hub speaks to the beginning of this span (X_3, Y_3, Z_3). That revolution axis Z_3 will be parallel to the past joint pivoting axis $Z \_2$, accordingly, $X \_3$ axis are along the as a relatable point typical for them. Those third axis Y_3 to finish the span is characterized as stated by RHR, the convergence of these axis speaks to those beginning for this span (X_3, Y_3, Z_3). That same methodology may be connected to the remaining span. The arm movement might make spoken to transformation matrix as taking after:

$$
\text { Arm-rotation }=\operatorname{Tr}_{\text {base }}^{\text {wrist }}\left(\theta_{1}, \theta_{2}, \theta_{3}\right)
$$


In general, $\mathrm{Tr}_{\mathrm{ii}}^{\mathrm{jj}}$ speaks to the conversion from $i \mathrm{i}^{\text {th }}$ area to $\mathrm{jj}{ }^{\text {th }}$ location. Also, $\mathrm{Tr}_{\text {base }}^{\text {wrist }}\left(\mathrm{T}_{\mathrm{zero}}^{\text {three }}\right)$ may be the orientation Furthermore position of the arm with admiration to the build direction frame, rely on upon those principals (3) angles $\left(\theta_{1}, \theta_{2}, \theta_{3}\right)$. Wrist movement (rotation) might a chance to speak to Eventually the transformation matrix starting with wrist to end effecter Likewise follow [9,10].

$$
\text { Wrist movement (rotation) }=\operatorname{Tr}_{\text {wrist }}^{\text {end-effector }}\left(\theta_{4}, \theta_{5}\right)
$$

Furthermore, $\operatorname{Tr}_{\text {wrist }}^{\text {end-effector }}\left(\operatorname{Tr}_{3}^{5}\right)$ will be roll and pitch of wrist joint coordinate frame, $\left(\theta_{4}, \theta_{5}\right)$. Note that $\operatorname{Tr}_{4}^{5}\left(\theta_{5}\right)$ maps between the roll and tool-tip coordinates, what is $\operatorname{more} \operatorname{Tr}_{3}^{4}\left(\theta_{4}\right)$ maps between the wrist pitch and roll coordinates. Therefore, the composite $\operatorname{Tr}_{3}^{4}\left(\theta_{4}\right)$ maps between wrist and end-effecter coordinates. Comparatively $\left(\operatorname{Tr}_{2}^{3}\left(\theta_{3}\right)\right)$ maps between elbow and wrist coordinates, $\left(\operatorname{Tr}_{1}^{2}\left(\theta_{2}\right)\right.$ maps between shoulder and elbow coordinates, Also, $\operatorname{Tr}_{0}^{1}\left(\theta_{1}\right)$ maps between base and shoulder coordinates. Therefore, those composite change $\operatorname{Tr}_{0}^{3}\left(\theta_{1} ; \theta_{2} ; \theta_{3}\right)$ wrist axis based base axis.

Those general result could make communicated as:

$$
[\text { Overall rotation }]=[\text { rotation of wrist }][\text { rotation of arm }]
$$

By Denavit-Hartenberg strategy, the position of tool-tip can be represented as:

$$
\operatorname{Tr}_{\text {From base }}^{\text {To end-effector }}\left(\theta_{1} \theta_{1}, \theta_{2}, \theta_{3}, \theta_{4}, \theta_{5}\right)=\mathrm{T}_{0}^{1}\left(\theta_{1}\right) \mathrm{T}_{1}^{2}\left(\theta_{2}\right) \mathrm{Tr}_{2}^{3}\left(\theta_{3}\right) \mathrm{T}_{3}^{4}\left(\theta_{4}\right) \mathrm{T}_{4}^{5}\left(\theta_{5}\right)=\mathrm{T}_{0}^{5}
$$

The rotation matrix $R_{3 \times 3}$ and position vector $P_{3 \times 1}$ of the (HTM) $\operatorname{Tr}_{0}^{5}$ is expressed as:

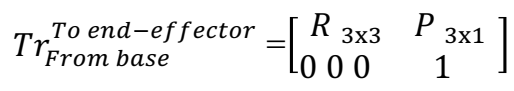

The upper matrix is divided into four parts, the first part is matrix $\mathrm{R}(3 \times 3)$ end-effector orientation, second part is matrix $\mathrm{P}(3 \times 1)$ end - effector position, third part is $\left(\begin{array}{lll}0 & 0 & 0\end{array}\right)$, and fourth part is ( 1$)$.

Thus, in the regulate kinematic solution, for at whatever provided for esteem of the joint angles $\theta$, the arm matrix $\mathrm{Tr}_{\text {base }}^{\text {end-effector }}$ might make assessed.

\section{Fuzzy Logic Controller TYPE-2 BASEd ON A PSO TEChNiQues (PSOT2FLC)}

Only the feature of type reducer block is the difference between Fuzzy Type - 2 and type 1. In the fuzzy logic type2, the first Input (error) and a second input (error change) of the robotic manipulator and they could make communicated as $[20,21]$ :

$$
\begin{gathered}
\mathrm{E}(\mathrm{k})=M_{r e f}(\mathrm{k})-\mathrm{M}(\mathrm{k}) \\
\text { Change of } \mathrm{E}(\mathrm{k})=\mathrm{E}(\mathrm{k})-\mathrm{E}(\mathrm{k}-1)
\end{gathered}
$$

The output controller is control action $u$ and represented as the torque. Table II represents the rule base used, where L, S, Z, P, and N acts for 'Large', 'Small', 'Zero', 'Positive', and 'Negative' respectively. Those MFs' in the Type-2 
FLC have been committed toward upper triangle what's more bring down triangle (by twofold triangles) comprising from claiming five end focuses. Subsequently that mf of Type-2 is no single amount Similarly as Type-1 fuzzy logic [20]. In Fig. 3, the four unsymmetrical membership function triangles are used. The MFs' can be written as:

$\{-1 \leq(-\mathrm{a} 1 ;-\mathrm{a} 2 ; 0 ; \mathrm{a} 2 ; \mathrm{a} 1) \geq 1\}$ Center MF;

$\{-1 \leq(-d ;-e ;-f ;-g ;-h ; h ; g ; f ; e ; d) \geq 1\}$--------Upper MF;

$\{-1 \leq(-\mathrm{e} ;-\mathrm{f} ;$-g; -h, g; -g; -h; g; f; e) $\geq 1\}$--------Lower MF.

TABLE II

TYPE-2 FLC RULE BASE

\begin{tabular}{|c|c|c|c|c|c|c|}
\hline \multicolumn{2}{|c|}{} & \multicolumn{6}{|c|}{$\Delta \mathbf{e}$} \\
\cline { 3 - 7 } \multicolumn{2}{|c|}{} & NL & NS & Z & PS & PL \\
\hline \multirow{4}{*}{$*$} & NL & NL & NL & NL & NS & Z \\
\cline { 2 - 7 } & NS & NL & NL & NS & Z & PS \\
\cline { 2 - 7 } & Z & NL & NS & Z & PS & PL \\
\cline { 2 - 7 } & PS & NS & Z & PS & PL & PL \\
\cline { 2 - 7 } & PL & Z & PS & PL & PL & PL \\
\hline
\end{tabular}

The PSO technique obtained the numerical values for the Lower, Upper and Center MFs'. The best position obtained so far (pbest) which remembers for each particle. It also receives the globally best position implemented by any particle in the population (gbest). The velocity which update particle can be evaluated by the distance and the velocity, and velocity for pbest\& gbest by (8).

$$
v_{i, j}(k+1)=w \cdot v_{i, j}(k)+C_{1} \cdot r_{1}\left(g_{\text {bost } j}-x_{i, j}(k)\right)+C_{2} \cdot r_{2}\left(p_{\text {bost }, j}-x_{i, j}(k)\right)
$$

where:

$\mathrm{vi}, \mathrm{j}(\mathrm{k})$ : velocity of particle for $\mathrm{i}$ in axis $\mathrm{j}$. Max. values for $j$ and $i$ in this work are 15 and 70 respectively.

$\mathrm{xi}, \mathrm{j}(\mathrm{k})$ : position of particle for $\mathrm{i}$ in axisj.

C1, C2: the values of acceleration $(0.12 \& 1.2)$.

w: the factor of inertia $(92 / 100)$.

r1, r2: random values $(0-$ to- 1$)$.

The position value is up to date using new position value and new velocity as

$$
x_{i, j}(k+1)=x_{i, j}(k)+v_{i, j}(k)
$$

The initial velocities and positions values of particle swarm are random. The fitness function is used as Integrated Absolute Error where:

$$
I A E=\int_{t_{z}}^{t_{f}}|e(t)| d t
$$


and it is calculated at the terminating of each iteration [11], [12]. The width of the membership function, i.e., FOU is auto varied, due to the input value [9]. Karnik Mendel [K-M] is used as type reducer from T2 to T1 [13,14]. The K$\mathrm{M}$ output is two values as output right and left $\left(y_{r}, y_{l}\right)$. The defuzzied output is the average of $y_{l}$ and yr. The PSO is used to design Type-1 FLC. The MFs triangles are used with same centers. Then, the triangle's base of the membership functions are the mathematics mean of the lower and upper membership functions of the fuzzy logic type-2, Table II shows the rule base.

The fuzzy type-2 with PSO is the second criteria (PSOT2FLC). PSO used to evaluate FOU and Gains. It can be achieved in four ways: method one is fixed for gains and foot of print uncertainty (Fixed FOU x Fixed GAIN), method two is variable gains and fixed foot of print uncertainty (Fixed FOU x Var. GAIN), method three variable FOU and fixed GAINS (Var. FOU x Fixed GAIN), and the last method variable GAINS and FOU (Var. FOU x Var. GAIN). All mfs' used in this procedure at the same head top for higher (upper) and down (lower) but error and error change will be controlled of the variable base for a triangle, as illustrated in Fig. 3. The numerical values of T2FLC MFs' characteristics are shown in Table III.

Fig. 4 shows the flowchart of robotic manipulator controller based PSO. The optimization starts with input the number of the iteration (80) and population (200), then selecting the number of parameters (thirty two) that need optimization for MFs' and I/O Gains, initializing PSO then using the position swarm, limitation for each parameters (24) and velocity update, then T1, or, T2FLC, then select the fitness equation and, finally, plot the time response of the system $[15,16]$.

\section{RM HARDWARE SYSTEM DESIGN}

\section{A. Input/Output Robotic Manipulator Hardware}

Five dc servo motors in the LV5250 Robotic manipulator, one to every join. Fig. 5 illustrates the proposed controller of the RM- structure.

The work is used interface electronic devise "PCI 1712/1711" through a personal computer. This model will determine the error change and error which will be distinguished between those zero point of the needed position of the particular join with the real position about join, then the control action has been generated and go to driving circuit [17], [18].

\section{B. PCI-1711, ADVANTECH, For Robotic Manipulator}

The card of Advantech type is implemented in this work to interfacing between Personal Computer and Robotic Manipulator in RTWT.

Utilized with RTW, contains (sixteen solitary finished) channels simple input, twelve-bit determination A/D converter dependent upon one hundred kilohertz inspecting rate, (two)channels simple output, sixteen channels advanced enter, sixteen channels advanced output, What's more sixteen bits determination. The project was connected by using fourteen digital output and ten digital input with RTW [13,14]. 
TABLE III

INPUT/OUTPUT NUMERICAL VALUES OF THE LOWER AND HIGHER MFS' T2FLC BASED PSO

\begin{tabular}{|c|c|c|c|c|c|c|}
\hline \multirow{2}{*}{ Parameter } & \multirow{2}{*}{ logical } & \multirow[b]{2}{*}{$\begin{array}{l}\text { Set } \\
\text { Center }\end{array}$} & \multicolumn{2}{|l|}{ UMF } & \multicolumn{2}{|l|}{ LMF } \\
\hline & & & $\begin{array}{l}\text { Left } \\
\text { bound }\end{array}$ & $\begin{array}{l}\text { Right } \\
\text { Bound }\end{array}$ & $\begin{array}{l}\text { Left } \\
\text { bound }\end{array}$ & $\begin{array}{l}\text { Right } \\
\text { bound }\end{array}$ \\
\hline \multirow{5}{*}{ Output } & $\mathrm{NL}$ & $\begin{array}{c}- \\
0.8980\end{array}$ & $\begin{array}{c}- \\
0.3537\end{array}$ & 0.3035 & 0.3004 & $\begin{array}{c}-0 . \\
2727\end{array}$ \\
\hline & NS & $\begin{array}{c}- \\
0.1949\end{array}$ & -0.4381 & $\begin{array}{c}- \\
0.3004\end{array}$ & $\begin{array}{c}- \\
0.3537\end{array}$ & $\begin{array}{c}- \\
0.3035\end{array}$ \\
\hline & $z$ & 0.00 & -0.3035 & 0.3035 & 0.2727 & $\begin{array}{c}- \\
0.2727\end{array}$ \\
\hline & PS & 0.1949 & -0.3004 & 0.4381 & 0.3035 & 0.3537 \\
\hline & PL & 0.8980 & -0.3035 & 0.3537 & 0.3004 & 0.2727 \\
\hline \multirow{5}{*}{$\begin{array}{c}\text { Input } \\
\Delta \theta \\
\&\end{array}$} & $\mathrm{NL}$ & $\begin{array}{c}- \\
0.8113\end{array}$ & -0.8790 & $\begin{array}{c}- \\
0.3463\end{array}$ & $\begin{array}{c}- \\
0.4723\end{array}$ & $\begin{array}{c}- \\
0.4166\end{array}$ \\
\hline & NS & $\begin{array}{c}- \\
0.3203\end{array}$ & -0.4723 & 0.8790 & 0.0586 & 0.4166 \\
\hline & $z$ & 0.0 & -0.4166 & 0.4166 & 0.0586 & 0.0586 \\
\hline & PS & 0.3207 & -0.8790 & 0.4723 & $\begin{array}{c}- \\
0.4166\end{array}$ & 0.0586 \\
\hline & PL & 0.8113 & 0.3463 & 0.8790 & 0.4723 & 0.4166 \\
\hline
\end{tabular}

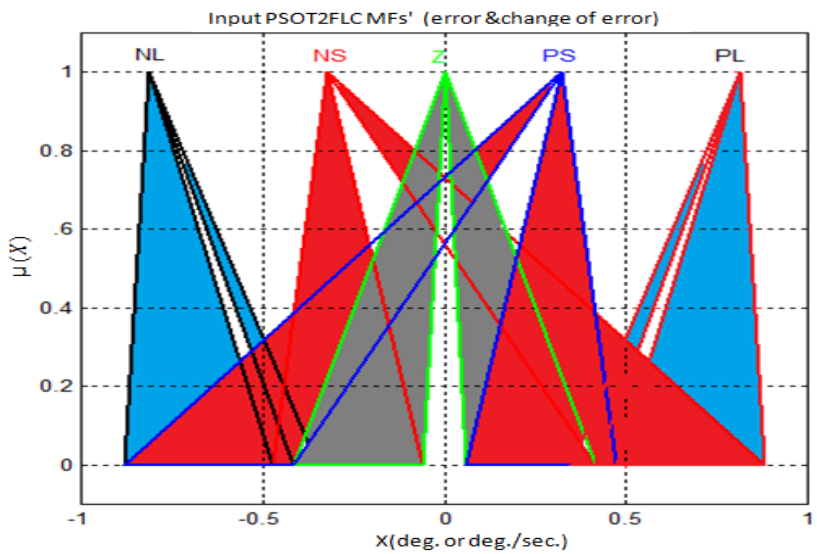

Figure 3. Optimized mfs' of psot $2 \mathrm{flc}$ (inputs error and change of error). 


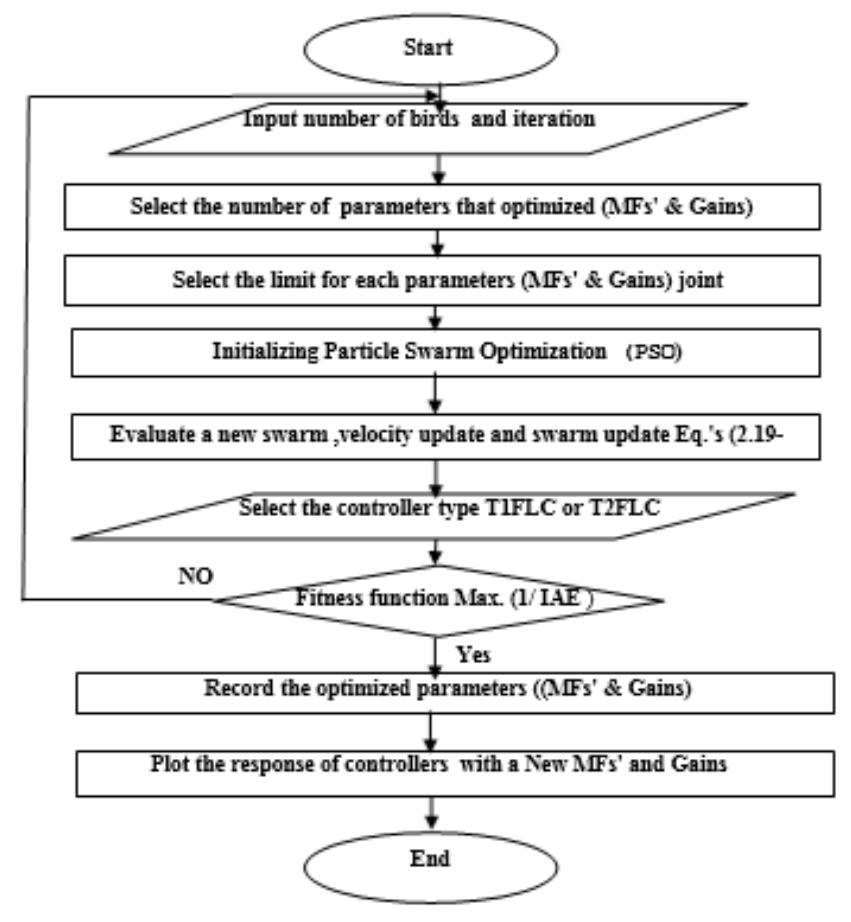

Figure 4. Flowchart of T2FLC based PSO

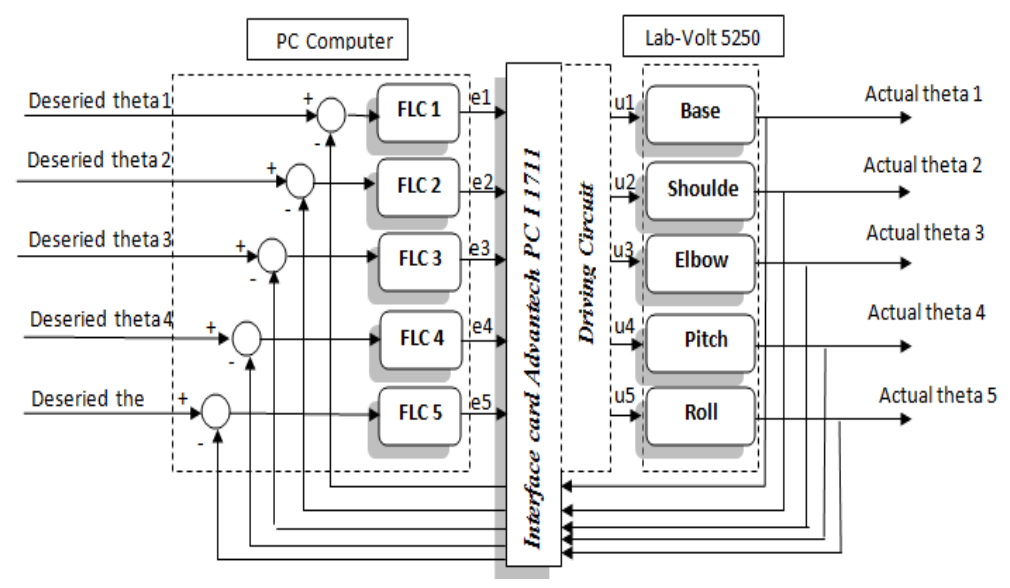

Figure 5. LV 5250 robot position controller.

Fig. 6 illustrates the controller of one joint Simulink model. These Simulink comprise for three blocks, the principal piece may be utilization with procedure those information signs the second square utilization with making those control movement, the most recent piece utilized to make advanced PWM.

Fig. 7 shows the block of M- function. Those T inputs are limit of max. the voltage that runs the motor of the robotic manipulator, MFs center, MFs bases, error change, error, and input/output gains, the controller output is the control command (u). 


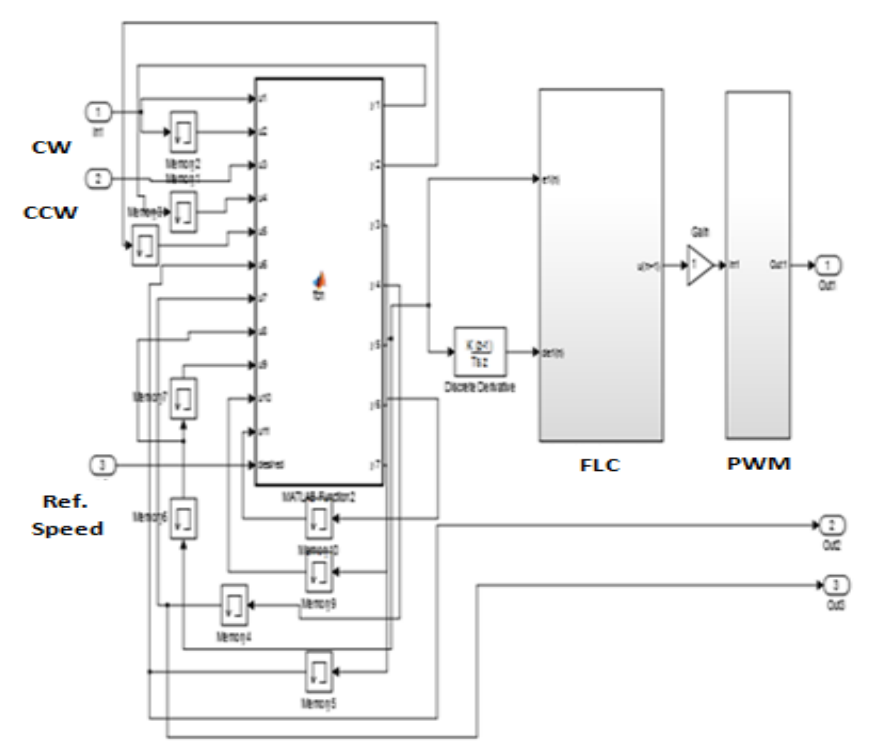

Figure 6. Robotic Manipulator controller model simulation for each joint.

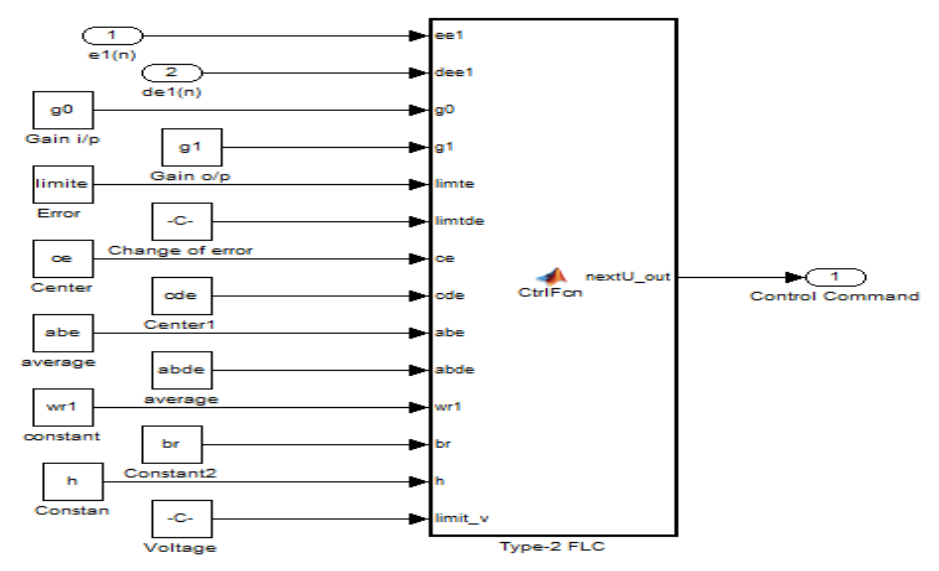

Figure 7. Type-2 FLC Simulink system.

Fig. 8 represents the experimental setup of Lab-Volt 5250 robotic manipulator that consist of (4) parts, part number one is personal computer, and the other part is electrical port of motor, last part is control unit [18].

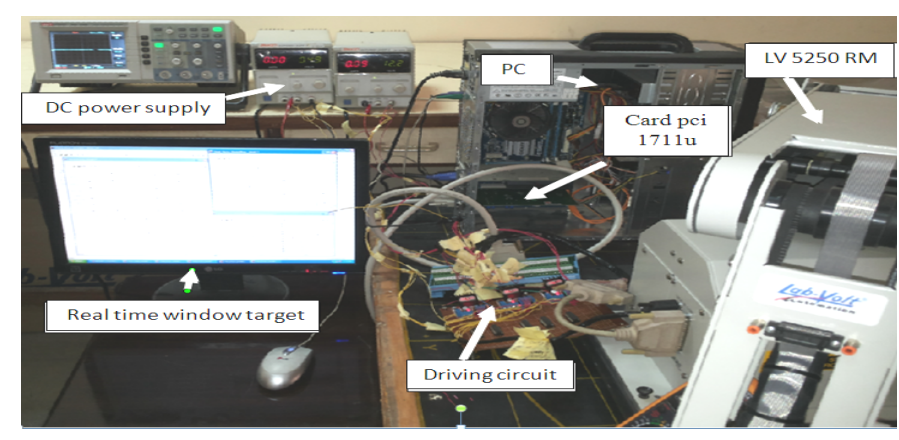

Figure 8. The setup of RM. 


\section{RM CONTROLLER EXPERIMENTAL RESULTS}

The framework comprises of pc and the interface card by means of the workstation PCI Advantech 1711, and in addition those RM. That interface card is utilized Likewise data acquisition What's more, sends the crisp values of the de joint motor.

1) DC motor drive: the speed of joint may be done by regulating the input voltage of the motor.

2) Position sensor: for each, the motor is supported toward a mechanical optical encoder. Those mathematical statements that are converting the sentiment sign starting with check those square wave unit on degree unit may be acquired by cur fitting strategy.

3) Identification reason of RM: the reason behind uses the identification is the model of FLC needed to optimization technique.

\section{A. Results of Identification}

The Matlab toolbox is used to get the results. Two criteria to find the performance of the models, percentage, fit \%, and Akaike's Final Prediction Error (FPE). The fit percentage is 94.611 \%, and Akaike's Final Prediction Error, FPE is 0.1014 , when sampling time is $10 \mathrm{~ms}$. Identification of non-linear parameters of motor joints is illustrated in Table IV.

TABLE IV

LAB-VOLT 5250 RM IDENTIFICATION OF THE JOINTS

\begin{tabular}{|c|}
\hline $\begin{array}{l}\text { A nonlinear ARX model is } \\
\begin{aligned} \mathrm{y}(\mathrm{k})+\mathrm{a}_{1} \mathrm{y}(\mathrm{k}-1)+\mathrm{a}_{2} \mathrm{y}(\mathrm{k}-2)+\cdots+\mathrm{a}_{\mathrm{na}} \mathrm{y}(\mathrm{k}-\mathrm{na}) \\
\quad \quad \quad \mathrm{b}_{1} \mathrm{u}(\mathrm{k}-1)+\mathrm{b}_{2} \mathrm{u}(\mathrm{k}-2)+\cdots+\mathrm{b}_{\mathrm{nb}} \mathrm{u}(\mathrm{k}-\mathrm{nb}+1)\end{aligned}\end{array}$ \\
\hline $\begin{array}{l}\text { Base joint eq. is } \\
\begin{array}{rl}y(k)+88.5 & y(k-1)-88.5 y(k-2) \\
& =7.5 u(k-1)+u(k-2)+80 u(k-2) * 838.33 y(k \\
& -1)^{2}\end{array}\end{array}$ \\
\hline $\begin{array}{l}\text { Shoulder joint eq. is } \\
\begin{aligned} & y(k)+y(k-1)-900 y(k-2) \\
& \quad=7.5 u(k-1)+7.565 u(k-2)+27 u(k-2) \\
& 8918.19 y(k-1)^{2}\end{aligned}\end{array}$ \\
\hline $\begin{array}{l}\text { Elbow joint eq. is } \\
\begin{aligned} & y(k)+y(k-1)-y(k-2) \\
& \quad=7.5 u(k-1)+7.5 u(k-2)+585 u(k-2) \\
& 8467.5 y(k-1)^{2}\end{aligned}\end{array}$ \\
\hline $\begin{array}{l}\text { Pitch joint eq. is } \\
\begin{aligned} y(k)+y(k-1)-31.75 y(k-2) \\
=8.2 u(k-1)+8.2 u(k-2)+27 u(k-2) * 412 y(k \\
-1)^{2}\end{aligned}\end{array}$ \\
\hline $\begin{array}{l}\text { Roll joint eq. is } \\
\begin{aligned} y(k)+y(k-1)-911 y(k-2) \\
\quad=7.5 u(k-1)+7.5 u(k-2)+502 u(k-2) \\
\\
\quad 864.8 y(k-1)^{2}\end{aligned}\end{array}$ \\
\hline
\end{tabular}

\section{B. Response of Base Joint}

The position point of the base joint is $140^{\circ}$. The several of controllers is used as:

1) The response of FLC base joint with different types: the type-1FLC or type-2FLC is implemented with the LV base joint. Fig. 9 illustrated the response of closed system and Table V illustrated the response parameters of the several types of controller. Table V represented the comparison between T2FLC and T1FLC from point of view rise time, settling time, and maximum over shoot. T2FLC is able to treat the high nonlinearity and uncertainty. 
TABLE V

RESPONSE OF BASE JOINT (TYPE-1FLC, TYPE-2FLC)

\begin{tabular}{|c|c|c|c|c|}
\hline Controller Types & $\mathrm{t}_{\boldsymbol{r}}$ (second) & $\mathrm{t}_{\mathrm{s}}($ second $)$ & $\% \mathrm{M}_{\boldsymbol{P}}$ & IAE \\
\hline Type-2FLC & 4.655 & 5.760 & 1.229 & 3.7296 \\
\hline Type-1FLC & 4.865 & 5.820 & 1.022 & 4.0220 \\
\hline
\end{tabular}

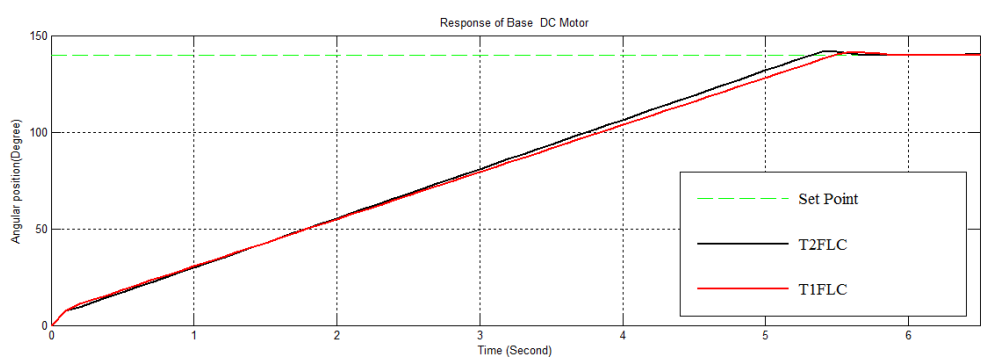

Figure 9. Base joint motor Response for T2FLC and T1FLC.

2) The response of base joint by four cases GAT2FLC: four responses T2FLC with several states of FOU and Gains illustrated in Fig. 10. From Table VI, it can be seen that the minimum value of the IAE, $t_{s}, t_{r}$ and MP for variable FOU and variable Gains.

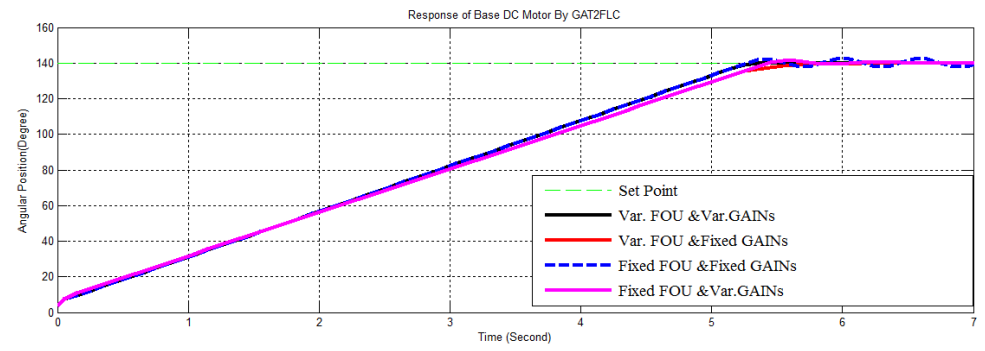

(a)

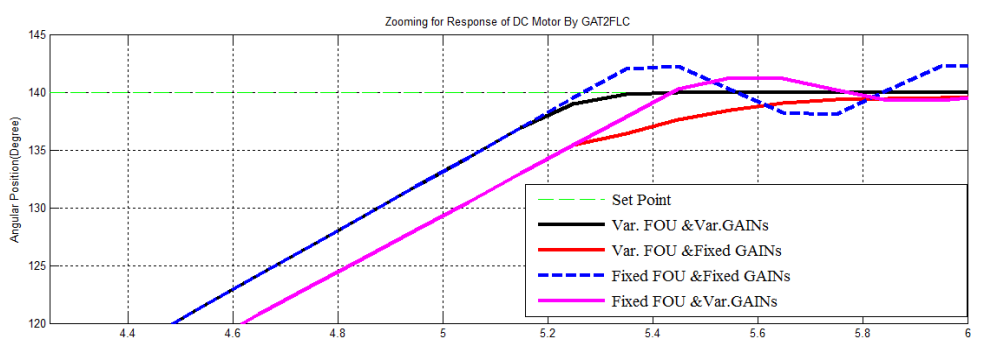

(b)

Figure 10. (a): Base joint motor response for four cases GAT2FLC, (b): Base motor response with four GAT2FLC 
TABLE VI

THE RESPONSE OF BASE JOINT MOTOR FOR FOUR GAT2FLC

\begin{tabular}{|c|c|c|c|c|}
\hline Type of Controller & $\mathrm{t}_{r}$ (sec.) & $\mathrm{t}_{s}$ (sec.) & $\mathrm{M}_{P} \%$ & IAE $^{*} 10 \mathrm{~K}$ \\
\hline Var.FOU \& Var.Gain & 4.798 & 5.500 & 0.00 & 3.7086 \\
\hline Var.FOU \& Fixed Gain & 4.987 & 6.980 & 0.0149 & 3.7185 \\
\hline Fixed FOU \&FixedGain & 4.798 & No & 1.5746 & 5.8721 \\
\hline Fixed FOU \&Var.Gain & 4.799 & 6.600 & 0.9713 & 3.7286 \\
\hline
\end{tabular}

3) The response of base joint for four PSOT2FLC: by utilizing that adaptability for useful PSO T2 FLC for the uncertainty of the model, by auto evolving worth about footprint of uncertainty. The base joint motor response using PSOT2FLC with four situations for several values of Gain and FOU are shown in Fig. 11. The Response characteristics illustrates in Table VII. It might a chance to be illustrates by Table VII, that the base quality of the IAE may be equivalent (3.7293), Furthermore quicker $t_{r}$ will be $(3.998 \mathrm{sec})$, yet the least qualified for $t_{s}$ is $(4.583)$ for that controller for variable FOU Furthermore variable Gain, those base quality of the greatest top overshoot will be for the same controller for variable FOU What's more Gain will be equivalent to $(0.00 \%)$.

TABLE VII

THE RESPONSE PARAMETERS OF BASE MOTOR WITH FOUR PSOT2FLC

\begin{tabular}{|c|c|c|c|c|}
\hline Type of Controller & $\mathrm{t}_{r}$ (sec.) & $\mathrm{t}_{s}(\mathrm{sec}$ ) & $\mathrm{M}_{P} \%$ & IAE$^{*} 10 \mathrm{~K}$ \\
\hline Var.FOU \& Var.Gain & 3.998 & 4.583 & 0.00 & 3.7293 \\
\hline Var.FOU \& Fixed Gain & 4.048 & 5.750 & 0.0117 & 3.7721 \\
\hline Fixed FOU \& Fixed Gain & 3.967 & No & $\begin{array}{c}\text { Limit } \\
\text { Cycle }\end{array}$ & 5.8845 \\
\hline Fixed FOU \& Var.Gain & 4.799 & 5.455 & 0.9189 & 3.9772 \\
\hline
\end{tabular}

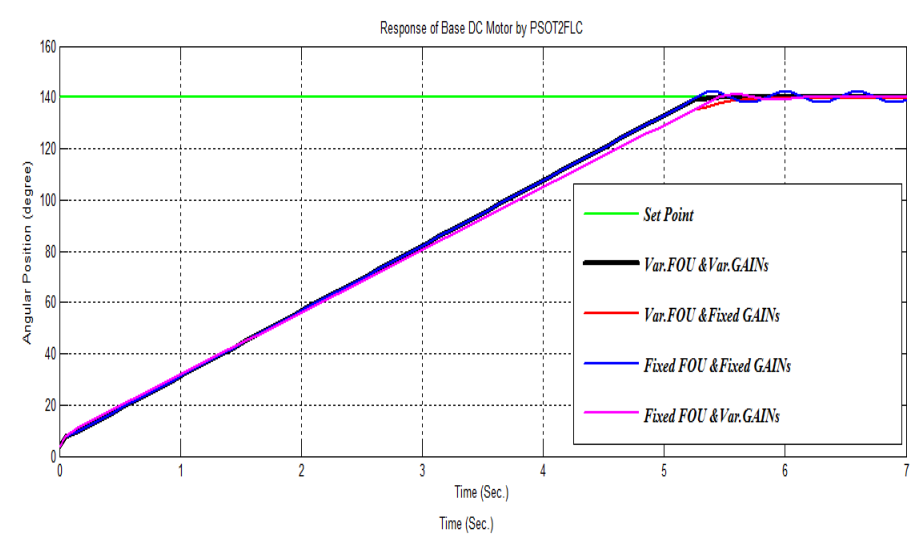

(a) 


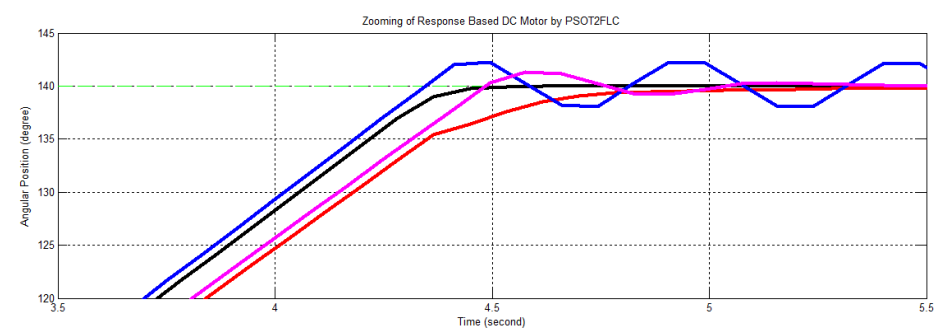

(b)

Figure 11. (a): Base motor response with four PSOT2FLCs, (b): Base motor response with four PSOT2FLC

4) The response of base joint using (PSO\& GA) T2FLC: the comparison between two responses by using PSO and GA is made. Fig. 12 shows that PSO response of T2FLC is the better than that of T1FLC.

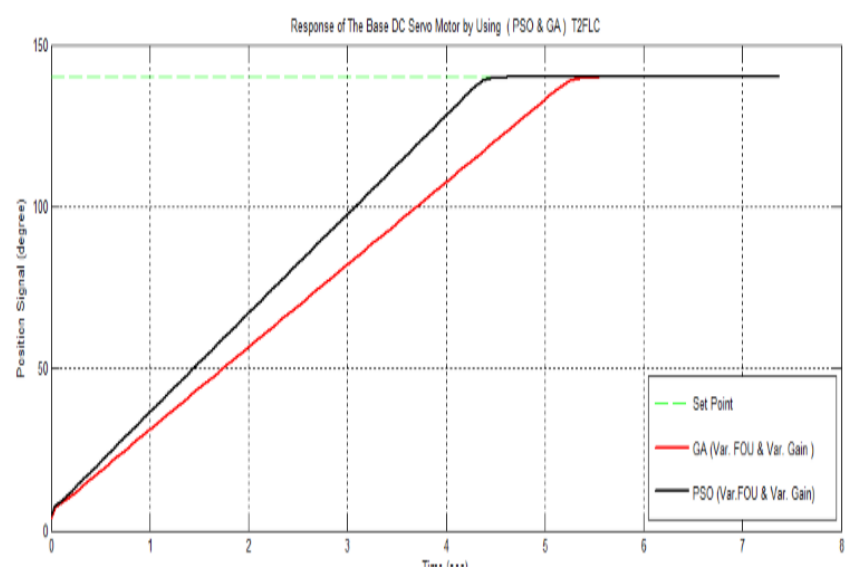

Figure 12. Base motor response for T2FLC based PSO \& GA with variable (FOU\& Gain)

5) Robot response for T2FLC, T1FLC: The Fuzzy logic controllers type one and two used regulator the joints of robot DC motor. The error numerical values (position and orientation) for the last joint is shown in Fig. 13, using (11) [19].

$$
M S E=\sum_{i=1}^{N} E_{i}^{2} / N
$$

Where, $M S E$ is mean square error, $\mathrm{E}$ is error and $\mathrm{N}$ is the number of samples.

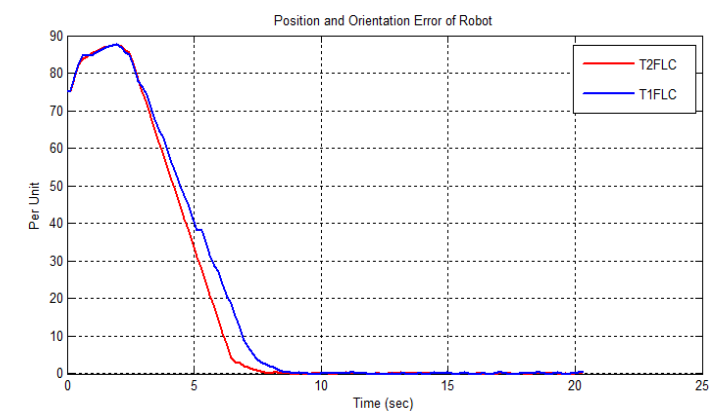

Figure 13. The error signal of position and orientation for LV 5250 RM. 
From Table VIII, the settling time for joints of robot with T2FLC $(8.301 \mathrm{sec})$ is less than T1FLC $(8.786 \mathrm{sec})$, and same matter apply to the IAE and MSE.

TABLE VIII

THE RESPONSE PARAMETERS OF ROBOTIC BASED T1FLC, T2FLC

\begin{tabular}{|c|c|c|c|}
\hline $\begin{array}{c}\text { Controller } \\
\text { types }\end{array}$ & $\mathrm{t}_{\boldsymbol{s}}$ & MSE*1k & IAE*10k $^{*}$ In second \\
\hline T1-FLC & 8.786 & 1.3705 & 6.4102 \\
\hline T2-FLC & 8.301 & 1.2762 & 5.446 \\
\hline
\end{tabular}

6) Robot Response based four PSOT2FLC: the robot response is illustrated in Fig. 14, for error signal of orientation and position. By using four changes PSOT2FLC with several states of the Gain and FOU the system is used to control all robot joints. The robotic system has the minimum values for settling time, and MSE based variable FOU and variable Gain. Table IX shows these parameters with numerical values.

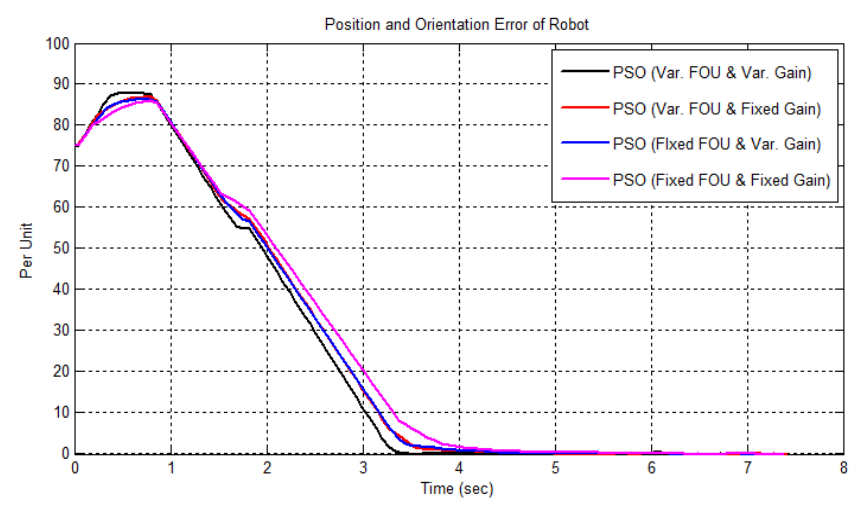

Figure 14. The error signal of position and orientation for robotic based PSOT2FLC.

TABLE IX

RESPONSE PARAMETERS OF ROBOT BASED FOUR PSOT2FLC,

\begin{tabular}{|c|c|c|c|}
\hline $\begin{array}{c}\text { Type of Controller } \\
\text { PSOT2FLC }\end{array}$ & $\mathrm{t}_{s}$ (sec.) & MSE $^{8} 1 \mathrm{k}$ & IAE $^{8} 10 \mathrm{~K}$ \\
\hline Var.FOU \& Var.Gain & 3.3630 & 1.1133 & 3.5925 \\
\hline Var.FOU \& Fixed Gain & 3.3390 & 1.1842 & 3.5101 \\
\hline $\begin{array}{c}\text { Fixed FOU \& Fixed } \\
\text { Gain }\end{array}$ & 4.9151 & 1.3212 & 3.6493 \\
\hline $\begin{array}{c}\text { Fixed FOU \& } \\
\text { Var.Gain }\end{array}$ & 5.0060 & 1.2028 & 3.6112 \\
\hline \multicolumn{2}{|c|}{ Postion snd Oriertsion Enor of Robot } \\
\hline
\end{tabular}

7) The overall time response of T2FLC with PSO for Lab-Volt (5250): According to Table X the second column are robotic manipulator with $\mathrm{P}-\mathrm{X}=262.0, \mathrm{P}-\mathrm{Y}=262.0, \mathrm{P}-\mathrm{Z}=986.0, \mathrm{\Theta}-\mathrm{P}=45^{\circ}, \mathrm{\Theta}-\mathrm{r}=90^{\circ}$, third column represents inverse kinematics with mat lab simulation (Proposed Method), and the fourth column represents the experimental 
numerical values, and the percentage error is in the fifth column. Overall the curve of error vector RM based PSO as Variable (FOU\& Gains) was illustrated in Fig. 15.

TABLE X

THE OVERALL NUMERICAL VALUES OF RESPONSE FOR LAB-VOLT (5250) ROBOTIC MANIPULATOR.

\begin{tabular}{|c|c|c|c|}
\hline $\begin{array}{l}\text { Required } \\
\text { values } \\
(\mathrm{mm})\end{array}$ & $\begin{array}{c}\text { IK by } \\
\text { Matlab } \\
\text { Simulated } \\
\text { values (deg.) }\end{array}$ & $\begin{array}{l}\text { Experimental } \\
\text { Values } \\
\text { (mm) }\end{array}$ & $\begin{array}{c}\text { Percentage Error } \\
\%\end{array}$ \\
\hline$P X=262.0$ & $\theta_{1}=45$ & $P X=261$ & 0.3 \\
\hline$P Y=262.0$ & $\theta_{2}=45$ & $\mathrm{PY}=261$ & 0.3 \\
\hline $\mathrm{PZ}=986.0$ & $\theta_{3}=45$ & $\mathrm{pZ}=987$ & 0.1 \\
\hline & $\theta_{4}=45$ & & 0.0 \\
\hline$\theta_{\mathrm{r}}=90^{\circ}$ & $\theta_{5}=90$ & $\theta_{\mathrm{I}}=90^{\circ}$ & 0.0 \\
\hline
\end{tabular}

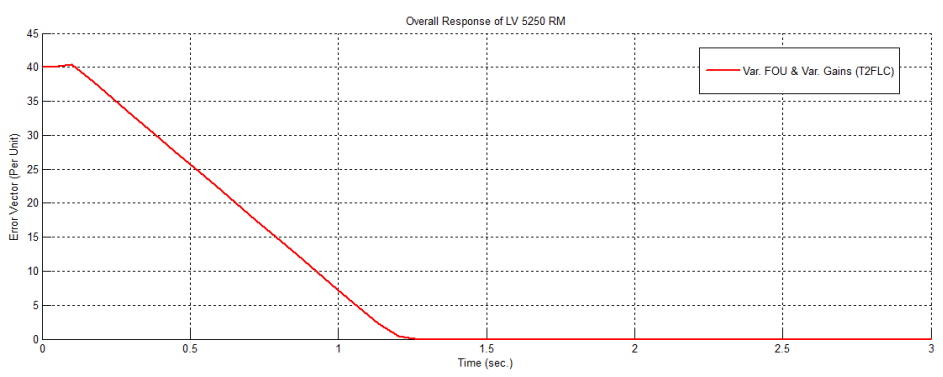

Figure 15 The overall time response of T2FLC LV $5250 \mathrm{RM}$

\section{CONCLUSION}

Because of the nonlinear qualities and parameter varieties done genuine environments, those type-2 fuzzy logic controller would be recommended will control those robotic controller joints motor. Those Emulating focuses might be reasoned for those responses at joints of the RM, according to the following points:

1) Type-2FLC performance is superior to Type-1FLC, from the perspective of the integral absolute error, settling time, which is more climbing (rising) time as stated in Table V.

2) PSOT2FLC performance is superior to T2FLC based GA, from a side of the point of seeing the integral absolute error, settling time, which is more rising time as stated by Table VI

3) The performance with variable (FOU\& GAIN) with PSOT2FLC is superior to other cases, starting with the perspective of the IAE, settling time, rising time as stated in Table VII.

4) Those overshoots $\left(M_{p}\right)$ about the joints, de servo motor for PSOT2FLC is zero low level over different controllers as stated in Table VII.

5) The values of IAE that utilized for PSOT2FLC may be short of what PSOT1FLC for joints as stated in Table VII

6) The base \& shoulder joints of the robotic manipulator are improved with the variable of member functions than symmetrical member functions' because they have high uncertainty. and nonlinearity. 
7) Generally, utilizing PSOT2FLC progressively provisions is superior to PSOT1FLC in spite of the fact that for variable width for MFs' that a constant rules base.

The controllers FLC type-2 are introduced, to the control of robotic manipulator arm. It can be concluded from the obtained results that:

1) T2FLC will be superior to T1FLC, from a side of the point of the settling time, IAE.

2) Those superior performances of the RM for T2FLC based PSO for not fixed MFs' \&Gains.

3) The triangles shape' are additional successful over other shapes about membership functions' in light of it is not difficult on auto evolving of a foot of pint uncertainty What's more well-known shape as stated by Table III.

4) Utilizing PSOT2FLC progressively requisitions is superior to PSOT1FLC uncommonly for RM that holds secondary uncertainty. and non-linearity.

\section{REFERENCES}

[1] L.H. Zadeh,"The Concept of a Linguistic Variable and its Application to Approximate Reasoning-", I . J. info. Sci. ,8(1), 199-249 ,1975.

[2] T.T. Erguzel," Fuzzy Controller Parameter Optimization Using Genetic Algorithm for a Real Time Controlled System ", The World Congress on Eng., London, U.K, 2(2), 2013.

[3] H. Shen, L. C. Chang," Online multistep - ahead inundation depth forecasts by recurrent NARX networks ", Hydro Earth System, 17, 935945, 2013.

[4] F.H. Nordin, F. H. Nagi, A. Z. Abidin," Comparison study of computational parameter values between LRN and NARX in identifying nonlinear systems", . Turkish J. of Elec. Eng. And comput.Sci.,21(9), 1151-1165,2013.

[5] R. Soto, O. Castillo, "A hybrid optimization method with PSO and GA to automatically design Type -1 and Type -2 fuzzy logic controllers ", International Journal Mach Learn and Cyber, Vol.272, No.1, 8, April, 2013.

[6] J. M. Mendel, H. Hagras, W. Tan, " Introduction to Type-2 Fuzzy Logic Control ", Published by Wiley \& Sons, Hobken, New Jersey, 2014.

[7] T. T. Erguzel," Fuzzy Controller Parameter Optimization Using Genetic Algorithm for a Real Time Controlled System ", The World Congress on Eng., London, U.K, 2(2),2013.

[8] P. Corke," Robotics Vision and Control", Springer - Verlag Berlin Heidelberg, 2013.

[9] R. Shanmugasundram, K. M. Zakariah, N. Yadaiah,"Implementation and Performance Analysis of Digital Controllers for Brushless DC Motor Drives", IEEE trans. On mechat., 19(1),2014. http://ieeexplore.ieee.org/document/6365820/

[10] H. Chaudhary, A. Parashar, ; R. Prasad,; N. Sukavanam," Velocity Observer Based Fuzzy PD+I Based Hybrid Force / Position Control of an Industrial Robot", IEEE Conf. in Eng. and Comput. Sci., Chandigarh,1-6, 2014. http://ieeexplore.ieee.org/document/6799648/

[11] M. A. Khanesar, O. Kayacan, W. Saeys, "Sliding Mode Type-2 Fuzzy Control of Robotic Arm Using Ellipsoidal Membership Functions" IEEE Conf. in Con., Istanbul,1-6, 2013. http://ieeexplore.ieee.org/document/6606393/

[12] I. Sirajuddin, L. Behera, T. M. McGinnity, S. Coleman," Image-Based Visual Servoing of a 7-DOF Robot Manipulator Using an Adaptive Distributed Fuzzy PD Controller ", IEEE Tran. on Mechat., 19(2),512-523, 2014. http://ieeexplore.ieee.org/document/6471828/

[13] B. Williams," An Introduction to Robotics", Mech. and Cont. of Robotic Manipulators, 2014.

[14] M.Z. Al-Faiz, A.A.Oglah," Type-2 Fuzzy Logic Controller Based Genetic Algorithm for the Position Control of DC Motor ", Intelligent Control and Automation.4, 108-113, 2013.

[15] M. Z.Al-Faiz, A.A.Oglah,:" Identification of Position DC Motor and Control Using Fuzzy Type-2 Based PSO:, Intern. J. of Comput. \& Tech., 11(1), 2013

[16] S. A. Ahmed, M. G.Petrov, "Trajectory Control of Mobile Robots using Type-2 Fuzzy - Neural PID Controller ", IFAC,138-143 ,2015.

[17] S. F. Toloue, M. R. Akbarzadeh, A Akbarzadeh, M. Jalaiean, "Position Tracking of a 3-PSP Parallel Robot Using Dynamic Growing Interval Type-2 Fuzzy Neural Control.", 1568-4946, 2015.

[18] P. S. Lonhe, Y.Singh , M. Santhakumar, B.M.Patre, L.M. Waghmare," Robust Nonlinear PID -Like Fuzzy Logic Control of a Parallel (2PRP-PPR) Manipulator ", ISA, 0019-0578,2016.

[19] S. Richa, G. Prerna, A. P. Mittal, "Design of Fractional - Order Hybrid Fuzzy Logic Controller for Robotic Manipulator", Arab J. Sci. Eng. 42(2), 739-750, 2017.

[20] A. Kumar,V. Kumar, "Artificial bee colony based design of the interval type-2 fuzzy PID controller for robot manipulator", TENCON IEEE conference, p.602-607, 2017.

[21] J. Andreu, F. Cao, H. Hagras "A Self- Adaptive Online Brain - machine interface of a Humanoid Robot Through a General type-2Inference System,"IEEE Transactions on fizzy Systems, p.101-116, V.26, issue 1, 2018. 